\title{
Fitossociologia e propriedades físicas da liteira em um ecossistema sucessional alterado pela agricultura itinerante na Amazônia oriental
}

Phytosociology and physical properties of the litter in an altered successional ecosystem in the eastern Amazon

\author{
H. B. dos Santos Junior*1; E. A. A. Araújo ${ }^{1}$; J. I. de M. Rodrigues²; W. B. R. \\ Martins $^{3}$; L. G. T. Rangel-Vasconcelos ${ }^{4}$; F. de A. Oliveira ${ }^{4}$ \\ ${ }^{1}$ Programa de pós-graduação em Ciências Florestais, Universidade Federal Rural da Amazônia, 66077-830, Belém- \\ PA, Brasil. \\ ${ }^{2}$ Laboratório de Manejo de Ecossistemas e Bacias Hidrográficas, Universidade Federal Rural da Amazônia, $66077-$ \\ 830, Belém-PA, Brasil \\ ${ }^{3}$ Programa de pós-graduação em Ciências Ambientais, Universidade do Estado do Pará, 66095-015, Belém-PA, Brasil \\ ${ }^{4}$ Instituto de Ciências Agrárias, Universidade Federal Rural da Amazônia, 66077-830, Belém-PA, Brasil \\ *eng.ftal.heliobrito@gmail.com \\ (Recebido em 14 de janeiro de 2021; aceito em 09 de junho de 2021)
}

\begin{abstract}
Este estudo teve como objetivo avaliar as propriedades físicas da liteira e a fitossociologia de uma floresta sucessional, 12 anos após o término do experimento de manipulação de recursos naturais, submetida a três tratamentos: Controle (CTL); Remoção de liteira (REM) e Irrigação (IRR). Realizamos a caracterização fitossociológica da comunidade (CAP > $15 \mathrm{~cm}$ ) e coletamos a liteira estocada no solo em dois períodos (chuvoso e menos chuvoso). As variáveis analisadas das propriedades físicas da liteira foram o estoque de liteira $\left(\mathrm{Mg} \mathrm{ha}^{-1}\right)$, densidade $\left(\mathrm{g} \mathrm{cm}^{-3}\right)$, espessura $(\mathrm{cm})$ e a capacidade de retenção hídrica (\%). As espécies Lacistema pubescens, Annona exsucca e Ocotea guianensis foram encontradas em todos os tratamentos. Os tratamentos CTL e IRR apresentaram as maiores densidades de indivíduos e similaridade. O índice de Shannon variou de 1,71 a 2,13 , porém não diferiu entre os tratamentos. O tratamento REM apresentou os maiores valores médios de estoque no período chuvoso $\left(8,66 \pm 0,42 \mathrm{Mg} \mathrm{ha}^{-1)}\right.$, enquanto no período menos chuvoso, os tratamentos com manipulação de recursos foram superiores ao controle. A capacidade de retenção hídrica foi semelhante entre os tratamentos, todavia constatamos um lento processo de restauração ecológica, que pode ser justificado pela proximidade às áreas urbanizadas. Acreditamos que a remoção de liteira pode retardar o desenvolvimento de plantas menos tolerantes às condições edáficas desfavoráveis, porém pode estimular adaptações morfofisiológicas. Após 12 anos do fim dos tratamentos, verificamos que a manipulação de recursos influenciou na recuperação das propriedades físicas da liteira, porém promove poucos efeitos nas características fitossociológicas.
\end{abstract}

Palavras-chave: biogeoquímico, floresta secundária, manejo da liteira.

This study aimed to evaluate the physical properties of the litter and the phytosociology of a successional forest, 12 years after the end of the experiment of manipulation of natural resources, submitted to three treatments: Control (CTL); Litter removal (REM) and Irrigation (IRR). We performed the phytosociological characterization $(\mathrm{CAP}>15 \mathrm{~cm})$ and collected the litter stored in the soil in two periods (rainy and less rainy). The variables analyzed for the physical properties of the litter were the litter stock $\left(\mathrm{Mg} \mathrm{ha}^{-1}\right)$, density $\left(\mathrm{g} \mathrm{cm}^{-}\right.$ $\left.{ }^{3}\right)$, thickness (cm) and the water retention capacity (\%). Lacistema pubescens, Annona exsucca and Ocotea guianensis were found in all treatments. The CTL and IRR treatments showed the highest density of individuals and similarity. Shannon's index ranged from 1.71 to 2.13 but did not differ between treatments. The REM treatment presented the highest average values of stock in the rainy season $\left(8.66 \pm 0.42 \mathrm{Mg} \mathrm{ha}^{-1}\right)$, while in the less rainy period, treatments with resource manipulation were superior to the control. The water retention capacity was similar between treatments, however we found a slow process of ecological restoration, which can be justified by the proximity to urbanized areas. We believe that the removal of litter can delay the development of plants that are less tolerant of unfavorable soil conditions, but an stimulate the morphophysiological adaptations. Twelve years after the end of the treatments, we found that the manipulation of resources influenced the recovery of the physical properties of the litter, with few effects on the phytosociological characteristics.

Keywords: biogeochemical, secondary forest, litter handling. 


\section{INTRODUÇÃO}

As florestas tropicais naturais contribuem com a maior parte da biodiversidade do planeta e por isso estão mais vulneráveis às atividades exploratórias [1]. Na Amazônia, as atividades econômicas desenvolvidas dependem diretamente da exploração dos recursos naturais, como mineração, extração madeireira e agropecuária. Além de degradar o ambiente devido à necessidade de supressão da vegetação, o avanço destas atividades contribui para exposição do solo, ocasionando impactos para os ciclos hidrológico e biogeoquímico. Nesse cenário, após distúrbios na vegetação original, o processo de sucessão ecológica (natural ou manejado pelo homem), dá origem às florestas secundárias, as quais passam a desempenhar um papel fundamental na conservação dos ecossistemas [2].

Dentre as características e benefícios desempenhados pelas florestas secundárias, destacam-se elevada produtividade de biomassa, capacidade de resiliência e o repositório de diversidade biológica, aumentando a provisão de matéria-prima e alimentos, de modo que o manejo correto destas florestas diminui a pressão exploratória sobre ecossistemas de floresta primária, podendo minimizar os impactos do desmatamento [2,3]. Devido à importância das florestas secundárias, muitos estudos buscam explicar o funcionamento destes ecossistemas [2, 4], através dos efeitos da manipulação de liteira para o desenvolvimento vegetal [5-7] e com a trajetória da restauração ecológica por meio de indicadores eficientes $[8,9]$.

A fitossociologia é um desses indicadores e auxilia na avaliação quali-quantitativa da estrutura da vegetação, facilitando o monitoramento das mudanças na composição florística da comunidade ao longo da sucessão ecológica [10]. Por meio de alguns parâmetros avaliados, como densidade, frequência, dominância e índice de valor de importância, é possível obter as características da estrutura horizontal de um ecossistema florestal e, dessa maneira, desenvolver um planejamento de gestão dos recursos naturais [11]. Outro indicador eficiente é a liteira, a qual é composta de todo material de origem vegetal e animal acumulado sobre o solo florestal como folhas, fragmentos de casca, galhos, flores, inflorescências, frutos e carcaças de animais mortos [12,13]. Dentro de um ecossistema, ela atua como um sistema de entrada e saída de nutrientes no ciclo biogeoquímico, onde a entrada é marcada pelo fluxo dos materiais vegetativos e sua decomposição, enquanto que a saída, pelo retorno dos nutrientes contido na liteira ao metabolismo das plantas [14-16].

As propriedades físicas da liteira no ecossistema florestal como estoque ou acúmulo, espessura, densidade e capacidade de retenção hídrica possuem potencial de modificação ecológica [17, 18], pois quando a liteira se encontra estocada favorece a germinação de espécies vegetais intolerantes a luminosidade, também denominadas de secundárias tardias e/ou clímax. Além disso, o estoque de liteira reduz as elevadas temperaturas do solo, beneficiando a atividade da fauna decompositora, contribuindo concomitantemente para a diminuição da erosão e lixiviação por meio da sua capacidade de retenção hídrica [19, 20].

As propriedades físicas da liteira são afetadas por fatores bióticos e abióticos, como composição florística, diversidade faunística, temperatura, precipitação pluviométrica e radiação solar [21]. As diferenças no estoque da liteira também podem estar relacionadas à intensidade dos distúrbios sofridos pela floresta $[22,23]$ e por isso, sua avaliação serve como indicador de níveis ecológicos satisfatórios para o equilíbrio e o funcionamento do ecossistemas previamente danificados. Em ecossistemas degradados, a liteira desempenha um papel fundamental na restauração de suas funções e estruturas, proteção contra processos erosivos [8]. Por outro lado, a remoção pode estimular a associação de plantas com fungos micorrízicos, com o intuito de otimizar a absorção de nutrientes [6]. Por isso, estudos que verifiquem os efeitos da manipulação de liteira são cada vez mais frequentes [24-26] e indispensáveis.

Na Amazônia, o projeto MANFLORA (Manipulação de Água e Nutrientes em Ecossistema de Floresta Secundária na Amazônia Oriental), no nordeste do Pará, foi elaborado para analisar como a disponibilidade de recursos naturais (água e nutrientes, por meio da remoção de liteira) interfere no desenvolvimento de ecossistemas florestais em estágio sucessional [24-32]. Os resultados do projeto demonstraram diferença no estoque de serapilheira e nutrientes entre os tratamentos. Neste cenário, 12 anos após o término do experimento conduzido pelo projeto MANFLORA, levantamos as seguintes questões científicas: 1) há diferença das propriedades físicas da liteira entre os tratamentos? e 2) qual tratamento apresenta melhores parâmetros fitossociológicos atualmente? 
Partindo da hipótese de que, se a manipulações de remoção de liteira favorece a germinação de sementes de espécies secundárias e clímax, espera-se que esse tratamento apresente melhores propriedades físicas da liteira e os melhores parâmetros fitossociológicos. Sendo assim, nosso objetivo foi avaliar o efeito residual desses tratamentos no que tange ao estoque de liteira e a fitossociologia de uma floresta secundária, 12 anos após o término do experimento de manipulação de água e nutrientes.

\section{MATERIAL E MÉTODOS}

\section{1. Área de estudo}

O trabalho foi realizado na Estação Experimental de Piscicultura de Água Doce, pertencente à Universidade Federal Rural da Amazônia - UFRA (1 $\left.{ }^{\circ} 19^{\prime} 16^{\prime \prime} \mathrm{S}, 47^{\circ} 57^{\prime} 50^{\prime \prime} \mathrm{W}\right)$, próximo ao planalto interfluvial do médio Rio Praquiquara, no baixo Rio Apeú e ao Km 63 da rodovia BR-316, no distrito de Apeú, município de Castanhal, nordeste do Estado do Pará [27, 33].

\subsubsection{Geologia e Geomorfologia}

Os solos são derivados da evolução diagenética dos sedimentos argilo-arenosos pertencentes à Formação Barreiras, no período Terciário da evolução. O relevo da região é em sua maior parte formada por superfície aplainada, dissecada em colinas de topo plano, com pequenas variação altimétrica [35].

\subsubsection{Pedologia}

Os solos da região são classificados como Latossolos Amarelos Distróficos de Fase Rochosa I (Concrecionário, Laterítico) apresentando baixa fertilidade natural e leve laminar erosão contendo $20 \%$ de argila, $74 \%$ de areia e $6 \%$ de silte nos primeiros $20 \mathrm{~cm}$ do solo $[29,35]$.

\subsubsection{Climatologia}

Segundo a classificação de Köppen, o clima na área de estudo é do tipo Af3, com precipitação pluviométrica média anual de 2.000 a $2.500 \mathrm{~mm}$, com a época mais chuvosa de dezembro a maio; e menos chuvosa de junho a novembro [37, 38]. No ano do experimento (2019), a precipitação anual foi de $2.500 \mathrm{~mm}$, com março sendo o mês mais chuvoso $(558,8 \mathrm{~mm})$ e setembro o menos chuvoso (65 mm), a temperatura diária variou de 25,2 a $27,9^{\circ} \mathrm{C}$ [38] (Figura 1). A umidade relativa do ar média foi de $81,37 \%$ [38].

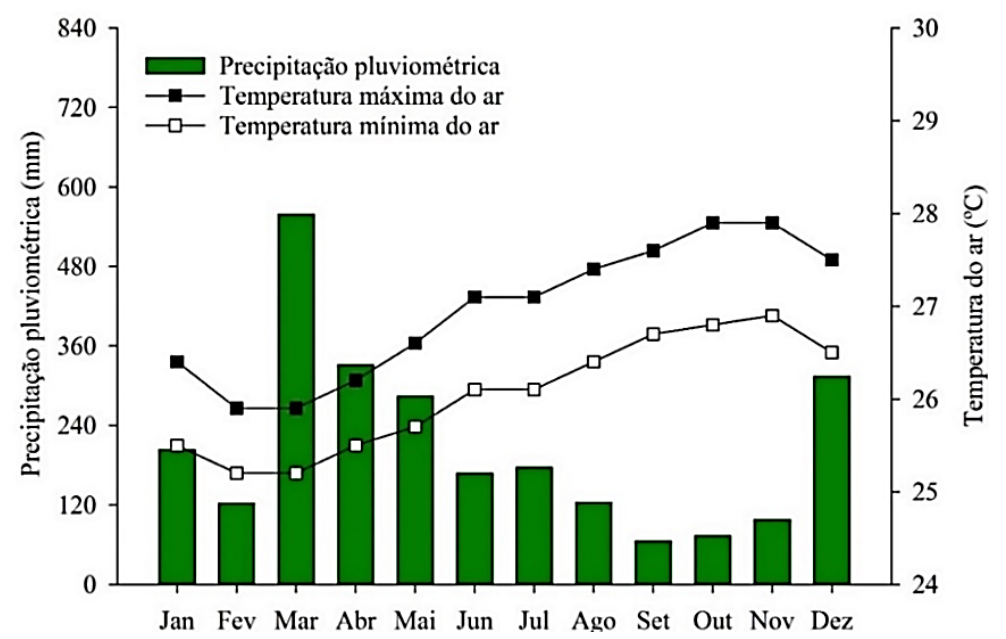

Figura 1: Variáveis climatológicas de precipitação pluviométrica e temperatura máxima e mínima na região da bacia do rio Apeú, no município de Castanhal, período de janeiro a dezembro de 2019. 


\subsubsection{Delineamento experimental da área de estudo}

$\mathrm{Na}$ área de estudo, historicamente, o distúrbio na floresta intacta ocorreu após múltiplos ciclos com plantio de Zea mays L. (milho), Manihot esculenta Crantz (mandioca) e Vigna unguiculata (L.) Walp (feijão caupi) seguido por cultivo itinerante e pousio, iniciou-se a regeneração natural da floresta em estudo no ano de 1987 [31, 32]. Em 1999, quando a floresta tinha 12 anos de idade, iniciaram-se os estudos do projeto MANFLORA (Manipulação de Água e Nutrientes em Ecossistema de Floresta Secundária na Amazônia Oriental). O experimento utilizou um delineamento inteiramente casualizado, sendo três tratamentos com quatro repetições cada. (Figura 2). No total, 12 parcelas foram instaladas, com dimensões de $20 \times 20 \mathrm{~m}$.

Os tratamentos variam de acordo com o manejo de recursos utilizado, sendo eles: irrigação (IRR), remoção de liteira (REM) e controle (CTL). O tratamento CTL não apresentou nenhuma interferência servindo de testemunha no estudo. O tratamento IRR era utilizada no período (geralmente julho a dezembro) da estação menos chuvosa, aplicada por fitas que possuíam aberturas espaçadas a cada $15 \mathrm{~cm}$, sendo que, cada fita distanciava-se inicialmente $4 \mathrm{~m}$ entre si. No entanto, visando melhorar a distribuição de água nas parcelas, essa distância foi encurtada para 2 m [30, 34].
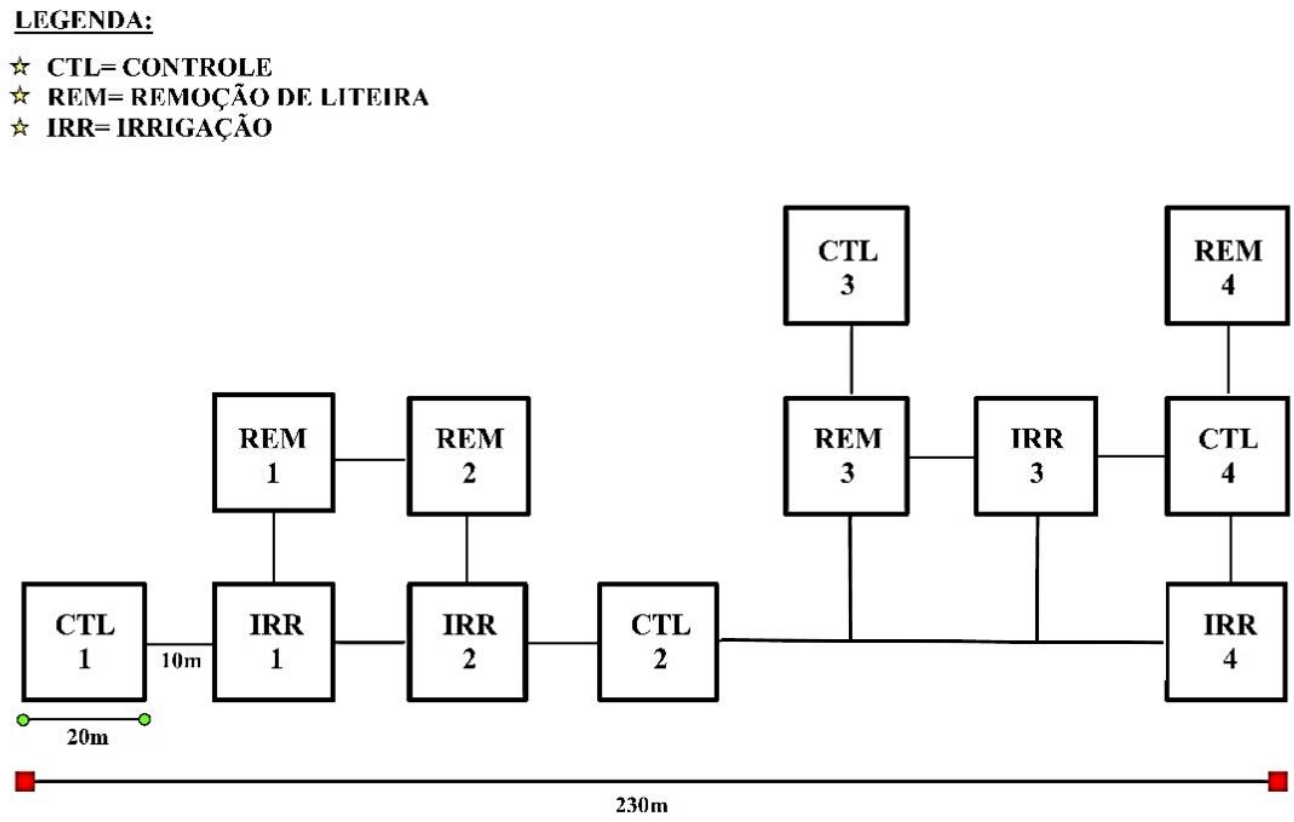

Figura 2: Design das parcelas experimentais do projeto MANFLORA $(C T L=$ controle $;$ REM $=$ remoção de liteira; IRR= irrigação de liteira), situado no planalto interfluvial na margem direita do Rio Praquiquara, afluente da margem direita do Rio Apeú na Estação de Piscicultura de Castanhal - UFRA, Castanhal, Pará.

Diariamente, nas parcelas com irrigação, eram aplicados $5 \mathrm{~mm}$ de água durante 30 minutos, totalizando na estação menos chuvosa um volume em torno de 630 a $790 \mathrm{~mm}$, representando um aumento de 100-200\% da entrada de água durante este período. Já nas parcelas do tratamento REM, toda liteira depositada no solo era retirada a cada duas semanas com auxílio de um ancinho, initerruptamente durante todo o experimento [34].

Os tratamentos foram aplicados entre os anos de 1999 e 2007. Em 2019, 12 anos após o término do experimento, foi realizado o estudo das propriedades físicas do estoque de liteira nas mesmas parcelas, com o intuito de averiguar os possíveis efeitos residuais (Figura 3). 


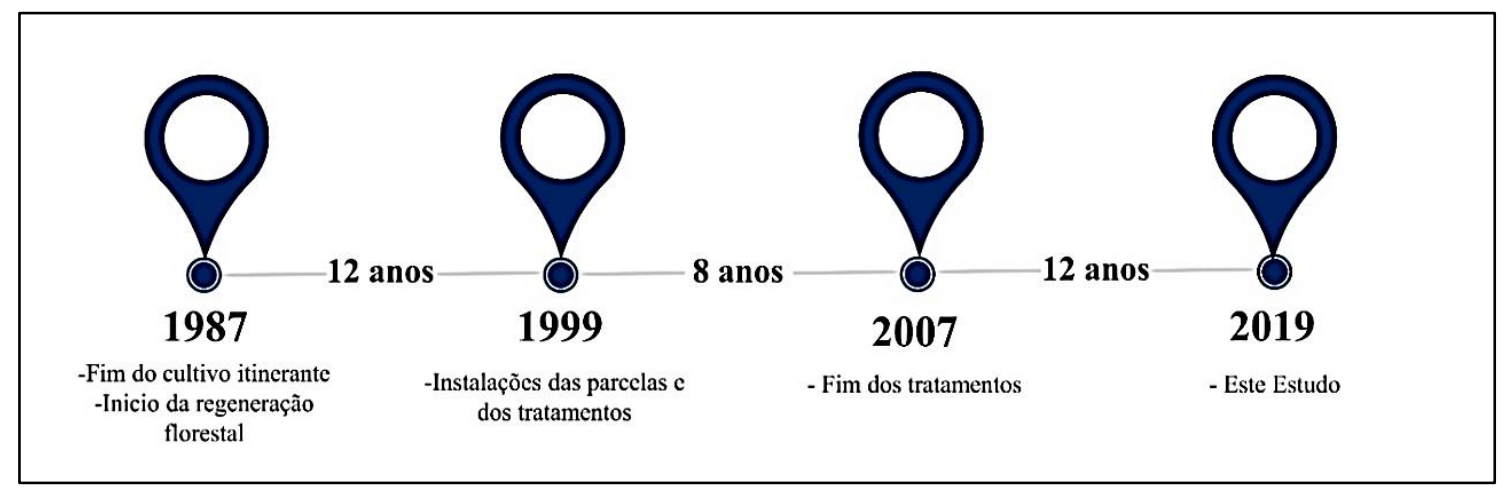

Figura 3: Ordem cronológica da área de estudo com ênfase nas parcelas experimentais $(C T L=$ controle; $R E M=$ remoção de liteira; IRR= irrigação) do projeto MANFLORA situada no planalto interfluvial na margem direita do Rio Praquiquara, afluente da margem direita do Rio Apeú na Estação de Piscicultura de Castanhal (EPC) - UFRA, Castanhal, Pará.

\subsection{Coleta de dados}

\subsubsection{Caracterização fitossociológica dos tratamentos}

No ano de 2019 foi demarcada uma sub-parcela de 10 x $10 \mathrm{~m}$, no interior de cada parcela do projeto MANFLORA, para obtenção de uma amostra da comunidade vegetal existente de cada tratamento. Desta forma, foi realizado um inventário florestal, com mensurações de indivíduos que apresentavam circunferência a altura do peito $(\mathrm{CAP})>15 \mathrm{~cm}$. Os indivíduos foram identificados in loco e quando necessário foi coletado material botânico para a identificação por comparação no herbário IAN da Embrapa Amazônia Oriental.

Os dados foram analisados através dos seguintes parâmetros fitossociológicos: densidade relativa (DR), frequência relativa (FR), dominância relativa (DoR), e índice de valor de importância (VI) [36, 40]. Todos os indivíduos foram classificados quanto ao grupo ecológico, em: Pioneiras, Secundárias e Clímax [39, 41]. Somado a isso, foram calculados os índices de diversidade de Shannon-Weaver (Equação 1) e de similaridade de Jaccard (Equação 2).

$$
\mathrm{H}^{\prime}=\Sigma(\mathrm{pi} * \mathrm{LN}(\mathrm{pi}))
$$

Em que: $H^{\prime}=$ Índice de Shannon-Weaver; pi= frequência relativa de uma espécie.

$$
\mathrm{S}_{\mathrm{j}}=\frac{\mathrm{a}}{(\mathrm{a}+\mathrm{b}+\mathrm{c})}
$$

Em que: $S_{j}=$ Índice de Jaccard; $a=$ número de espécie em comum entre os tratamentos; $b=$ número de espécies que existe no tratamento 1 e não existe no tratamento 2; c= número de espécies que existem no tratamento 2 e não existe no tratamento 1.

\subsubsection{Coleta da liteira}

Em cada parcela foram coletadas 10 amostras de liteira, sendo 2 coletas no período chuvoso (dezembro e março), e 2 no período menos chuvoso (junho e setembro), totalizando 80 amostras por tratamento em cada período. Para a coleta, foi utilizado um coletor metálico de $0,25 \times 0,25 \mathrm{~m}$ $\left(0,0625 \mathrm{~m}^{2}\right)$ com $8 \mathrm{~cm}$ de altura e volume de coleta de $5000 \mathrm{~cm}^{3}$. Além disso, foi utilizada uma régua centimétrica para medir a espessura da liteira nos quatros lados do coletor e, com auxílio de um facão e uma espátula a liteira foi retirada do solo. Todo o material coletado foi alocado em sacos plásticos, identificados e transportados para o laboratório da Universidade Federal Rural da Amazônia - UFRA. 


\subsubsection{Procedimento laboratorial}

a) Capacidade de retenção hídrica

A capacidade de retenção hídrica $(\mathrm{CRH})$ foi analisada pela metodologia descrita por Blow (1955) [42]. Nesta análise, as amostras foram submersas em água por cerca de 90 minutos. Em seguida depositadas em bandejas inclinadas a aproximadamente a $45^{\circ}$ por cerca de 30 minutos, para a retirada do excesso de água. As amostras foram pesadas em balança de precisão para obtenção da massa úmida e levadas a estufa a $70{ }^{\circ} \mathrm{C}$ por $36 \mathrm{~h}$ para a obtenção da massa seca. Com isso, o valor da taxa de retenção hídrica foi encontrado pela Equação 3.

$$
\mathrm{CRH}(\%)=\frac{\mathrm{MU}-\mathrm{MS}}{\mathrm{MS}} \times 100
$$

Em que: $C R H=$ Capacidade de Retenção Hídrica (\%), $M U=$ Massa úmida após submersão em água $(\mathrm{g}), M S=$ Massa seca $(\mathrm{g})$.

b) Estoque de liteira

Após análise de capacidade de retenção hídrica, a liteira foi separada em 2 frações: Folhoso (folhas, frutos, sementes e flores) e lenhoso (galhos). Posteriormente, as amostras foram acondicionadas em estufa com circulação e renovação de ar (SL - 102) a uma temperatura de $70{ }^{\circ} \mathrm{C}$ durante $36 \mathrm{~h}$ e, em seguida, foram pesadas em balança analítica (Ohaus - ARA 520) com precisão de $0,01 \mathrm{~g}$. A quantificação do estoque de liteira foi determinada pela razão total entre a massa seca e a área do coletor, e para converter o resultado para hectare, multiplicou-se o resultado pelo fator de conversão 0,01 (Equação 4) [12].

$$
\mathrm{Et}=\frac{\mathrm{Msl}}{\mathrm{A}} \times 0,01
$$

Em que: Et = estoque de liteira $\left(M g h a^{-1}\right) ; M s l=$ massa seca da liteira $(g) ; A=$ Área do coletor $\left(m^{2}\right)$.

c) Espessura da liteira

A espessura da liteira foi calculada pela média aritmética da altura das 4 leituras por amostra (Equação 5) [12].

$$
\mathrm{Es}=\frac{\sum_{\mathrm{i}=1}^{4} \mathrm{Li}}{\mathrm{n}}
$$

Em que: Es = Estimativa espessura da liteira (cm); Li = leitura da espessura em cada lado do coletor metálico $(\mathrm{cm})$; e $n=$ número de leituras por amostra.

d) Densidade da liteira

A densidade da liteira foi calculada pela razão entre a massa seca e o volume do coletor (Equação 6) $[12]$.

$$
\mathrm{D}=\frac{\mathrm{Msl}}{\mathrm{V}}
$$

Em que: D= Densidade da liteira $\left(\mathrm{g} \mathrm{cm}^{-3}\right), M s l=$ massa seca da liteira $(\mathrm{g}), V=$ volume do coletor $\left(\mathrm{cm}^{-3}\right)$. 


\subsection{Análise estatística}

Para as variáveis de massa seca do estoque $\left(\mathrm{Mg} \mathrm{ha}^{-1}\right)$, espessura $(\mathrm{cm})$, densidade $\left(\mathrm{g} \mathrm{cm}^{-3}\right)$ e capacidade de retenção hídrica da liteira (\%) foi utilizado um delineamento inteiramente casualizado em arranjo fatorial $3 \times 2$ (tratamentos x períodos).

Os dados de todas as variáveis físicas de liteira foram submetidos ao teste de normalidade de Shapiro-Wilk ( $p>0,05)$ e o teste de homocedasticidade de variância de Bartlett ( $p>0,05)$. Atendido a esses pressupostos, foi realizado a análise de variância - ANOVA $(\mathrm{p}<0,05)$ e caso necessário o teste pos-hoc de Tukey para comparação entre as médias $(\mathrm{p}<0,05)$. Os programas utilizados para as análises e elaboração de gráficos foi o SigmaPlot 14.0.

\section{RESULTADOS}

\subsection{Caracterização fitossociologia da vegetação arbórea}

No tratamento CTL foram registrados 114 indivíduos com a riqueza de 32 espécies e 19 famílias. No REM, encontramos as menores riquezas de espécies e famílias, onde foram registrados 85 indivíduos divididos em 22 espécies e 15 famílias. Já no tratamento IRR foram contabilizados 110 indivíduos distribuídos em 29 espécies e 17 famílias. A abundância de indivíduos para CTL, REM e IRR foi de 2.850 ind ha $^{-1}, 2.125$ ind ha $^{-1} \mathrm{e} 2.750$ ind ha $^{-1}$, respectivamente. Apesar da maior riqueza de espécies no tratamento CTL, os índices de diversidade de Shannon-Weaver variaram de 1,71 a 2,13 para REM e IRR, respectivamente, porém não houve diferença significativa entre os tratamentos $\left(\mathrm{F}_{2 ; 9}=1,26 ;\right.$ p-valor $\left.=0,33\right)$ (Tabela 1). Por outro lado, estes dois tratamentos apresentaram a menor similaridade de Jaccard $(0,31)$, enquanto a maior, foi observada para CTL e IRR $(0,39)$ (Tabela 2).

Tabela 1: Índices de diversidade de Shannon-Weaver nos tratamentos $C T L=$ controle, $R E M=$ remoção de liteira e IRR= irrigação, situada nos experimentos do projeto MANFLORA na Estação de Piscicultura de Castanhal (EPC) - UFRA, Castanhal, Pará.

\begin{tabular}{cc}
\hline Tratamento & Shannon-Weaver \\
\hline CTL & $2,04 \mathrm{~ns}$ \\
REM & $1,71 \mathrm{~ns}$ \\
IRR & $2,13 \mathrm{~ns}$ \\
\hline
\end{tabular}

Tabela 2: Índice de similaridade de Jaccard nos tratamentos $C T L=$ controle, $R E M=$ remoção de liteira e $I R R=$ irrigação, situada nos experimentos do projeto MANFLORA na Estação de Piscicultura de Castanhal (EPC) - UFRA, Castanhal, Pará.

\begin{tabular}{cccc}
\hline Tratamento & CTL & REM & IRR \\
\hline CTL & 1 & 0,38 & 0,39 \\
REM & & 1 & 0,31 \\
IRR & & & 1 \\
\hline
\end{tabular}

Entre as famílias mais representativas da análise fitossociológica do tratamento CTL, Annonaceae foi a mais representativa com três espécies, correspondendo a um total de $30 \%$. No entanto, foram as espécies Lacistema pubescens Mart. (Lacistemataceae) e Cupania scrobiculata Rich. (Sapindaceae) que apresentaram maiores densidades e frequências relativas (Tabela 3); com maior ênfase para L. pubescens, no qual constatou também resultados relevantes para dominância relativa (14,58\%) e índice de valor de importância 16,83\% (Tabela 3).

Constatamos que as famílias Annonaceae e Fabaceae somaram juntas $50 \%$ das espécies contidas no tratamento REM. Por outro lado, as espécies Lacistema pubescens Mart. (Lacistemataceae) e Ocotea guianensis Aubl. (Lauraceae) evidenciaram resultados expressivos de densidade e 
dominância relativa (Tabela 3). Além disso, verificamos que essas espécies representaram juntas 46,63\% do VI, e que L. pubescens foi a única que esteve presente em todas as parcelas amostradas, com $11,76 \%$ de frequência relativa. No tratamento IRR, a família Fabaceae atingiu os maiores registros de espécies dentre as famílias mais importantes para o ecossistema, com Amphiodon effusus Huber apresentando melhores porcentagens de ocupação na área $(15,07 \%)$ comparado a dominância relativa das outras espécies listadas. Em contrapartida, encontramos para Pourouma guianensis os maiores valores para DR (\%), FR (\%) e VI com 20,91\%, 9,09\% e 12,94\%, respectivamente (Tabela 3 ).

Tabela 3: Fitossociologia das dez espécies com maiores índices de valores de importância (VI), nos tratamentos $C T L=$ controle, $R E M=$ remoção de liteira e $I R R=$ irrigação, situada nos experimentos do projeto MANFLORA na Estação de Piscicultura de Castanhal (EPC) - UFRA, Castanhal, Pará.

\begin{tabular}{|c|c|c|c|c|c|c|c|}
\hline \multicolumn{8}{|c|}{ Parâmetros fitossociológicos no tratamento CTL } \\
\hline Família & Espécie & $\mathrm{N}$ & $\mathrm{DR}(\%)$ & $\mathrm{FR}(\%)$ & $\operatorname{DoR}(\%)$ & VI $(\%)$ & GE \\
\hline Lacistemace & Lacistema pubescens Mart. & 3 & 28,95 & 6,98 & 14,58 & 16,83 & $\mathrm{~S}$ \\
\hline Sapindaceae & Cupania scrobiculata Rich. & 1 & 11,4 & 6,98 & 4,67 & 7,68 & $\mathrm{C}$ \\
\hline Connaraceae & Connarus perrottetii var. angustifolius & 7 & 6,14 & 4,65 & 9,76 & 6,85 & $\mathrm{P}$ \\
\hline Annonaceae & Annona exsucca DC. & 8 & 7,02 & 4,65 & 7,94 & 6,54 & S \\
\hline Annonaceae & Guatteria punctata (Aubl.) R. A. Howard & 3 & 2,63 & 4,65 & 5,61 & 4,3 & $\mathrm{C}$ \\
\hline Annonaceae & Annona paludosa Aubl. & 3 & 2,63 & 6,98 & 3,19 & 4,27 & $\mathrm{P}$ \\
\hline Lauraceae & Ocotea guianensis Aubl. & 1 & 0,88 & 2,33 & 8,58 & 3,93 & $\mathrm{C}$ \\
\hline Anacardiace & Tapirira guianensis Aubl. & 1 & 0,88 & 2,33 & 8,27 & 3,82 & $\mathrm{P}$ \\
\hline Lecythidacea & Couratari stellata A.C.Sm. & 3 & 2,63 & 2,33 & 5,59 & 3,52 & $\mathrm{C}$ \\
\hline Fabaceae & Stryphnodendron pulcherrimum (Willd.) & 2 & 1,75 & 2,33 & 5,93 & 3,34 & $\mathrm{P}$ \\
\hline Outras & 22 & 4 & 35,09 & 55,79 & 25,88 & 38,92 & - \\
\hline \multicolumn{8}{|c|}{ Parâmetros fitossociológicos tratamento REM } \\
\hline Família & Espécie & $\mathrm{N}$ & $\mathrm{DR}(\%)$ & FR $(\%)$ & $\operatorname{DoR}(\%)$ & VI $(\%)$ & GE \\
\hline Lacistemace & Lacistema pubescens Mart. & 2 & 34,12 & 11,76 & 32,38 & 26,09 & $\mathrm{~S}$ \\
\hline Lauraceae & Ocotea guianensis Aubl. & 1 & 17,65 & 8,82 & 35,76 & 20,74 & $\mathrm{C}$ \\
\hline Annonaceae & Guatteria punctata (Aubl.) R. A. Howard & 8 & 9,41 & 8,82 & 4,37 & 7,54 & $\mathrm{C}$ \\
\hline Sapindaceae & Cupania scrobiculata Rich. & 8 & 9,41 & 5,88 & 2,04 & 5,78 & $\mathrm{C}$ \\
\hline Fabaceae & Inga flagelliformis (Vell.) Mart. & 4 & 4,71 & 8,82 & 2,06 & 5,20 & S \\
\hline Anacardiace & Tapirira guianensis Aubl. & 2 & 2,35 & 5,88 & 3,54 & 3,93 & $\mathrm{P}$ \\
\hline Annonaceae & Annona exsucca DC. & 2 & 2,35 & 5,88 & 2,29 & 3,51 & $S$ \\
\hline Fabaceae & Abarema jupunba (Willd.) Britton \& Killip & 3 & 3,53 & 2,94 & 3,04 & 3,17 & $\mathrm{~S}$ \\
\hline Annonaceae & Xylopia nitida Dunal & 1 & 1,18 & 2,94 & 3,68 & 2,60 & $\mathrm{C}$ \\
\hline Vochysiacea & Vochysia guianensis Aubl. & 1 & 1,18 & 2,94 & 3,00 & 2,37 & $\mathrm{~S}$ \\
\hline Outras & 12 & 1 & 14,11 & 64,68 & 7,84 & 19,07 & - \\
\hline \multicolumn{8}{|c|}{ Parâmetros fitossociológicos no tratamento IRR } \\
\hline Família & Espécies & $\mathrm{N}$ & $\mathrm{DR}(\%)$ & FR (\%) & $\operatorname{DoR}(\%)$ & VI $(\%)$ & GE \\
\hline Urticaceae & Pourouma guianensis Aubl. & 2 & 20,91 & 9,09 & 8,81 & 12,94 & $\mathrm{P}$ \\
\hline Lacistemace & Lacistema pubescens Mart. & 1 & 12,73 & 9,09 & 5,37 & 9,06 & $\mathrm{~S}$ \\
\hline Fabaceae & Amphiodon effusus (Huber) & 1 & 9,09 & 2,27 & 15,07 & 8,81 & $S$ \\
\hline Lauraceae & Ocotea guianensis Aubl. & 6 & 5,45 & 4,55 & 13,89 & 7,96 & $\mathrm{C}$ \\
\hline Annonaceae & Annona exsucca DC. & 7 & 6,36 & 6,82 & 6,20 & 6,46 & S \\
\hline Annonaceae & Guatteria punctata (Aubl.) R. A. Howard & 6 & 5,45 & 6,82 & 5,93 & 6,07 & $\mathrm{C}$ \\
\hline
\end{tabular}


Tabela 3: (continuação)

\begin{tabular}{llllllll}
\hline Fabaceae & Inga flagelliformis (Vell.) Mart. & 6 & 5,45 & 4,55 & 2,32 & 4,11 & $\mathrm{~S}$ \\
Fabaceae & Abarema jupunba (Willd.) Britton \& Killip & 5 & 4,55 & 2,27 & 5,32 & 4,05 & $\mathrm{~S}$ \\
Vochysiacea & Vochysia guianensis Aubl. & 3 & 2,73 & 2,27 & 6,88 & 3,96 & $\mathrm{~S}$ \\
Salicaceae & Casearia arborea (Rich.) Urb. & 3 & 2,73 & 4,55 & 4,00 & 3,76 & $\mathrm{~S}$ \\
\hline Outras & \multicolumn{1}{c}{19} & 2 & 24,55 & 47,72 & 26,21 & 32,82 & - \\
\hline
\end{tabular}

Onde: N= número absoluto de indivíduos; DR= Densidade Relativa; $F R=$ Frequência Relativa; DoR= Dominância Relativa; VI= Índice de Valor de Importância; G= Grupo Ecológico.

Quanto aos grupos ecológicos, percebemos que em todos os tratamentos o maior número de espécies foi classificado como secundária. No grupo das pioneiras, a maior porcentagem esteve no tratamento IRR. Já as espécies clímax, esteve mais representada no tratamento REM, com uma distribuição mais equitativa entre os grupos ecológicos (Figura 4).
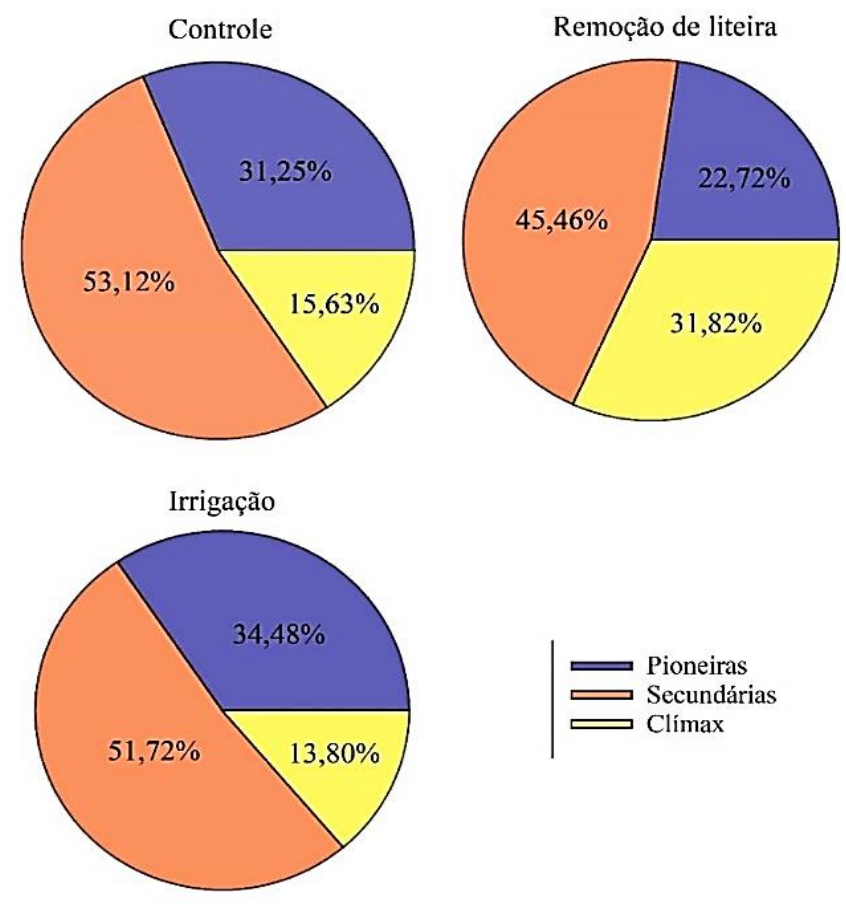

Figura 4: Distribuição percentual dos grupos ecológicos das espécies encontradas nos tratamentos $C T L=$ Controle; REM= Remoção de liteira; IRR= Irrigação, situada nos experimentos do projeto MANFLORA, na Estação de Piscicultura de Castanhal-UFRA, Castanhal, Pará.

\subsection{Propriedades físicas da liteira}

A liteira estocada entre os tratamentos foi significativamente diferente nos dois períodos avaliados (Figura 5). O tratamento REM apresentou os maiores valores médios de estoque no período chuvoso com $8,66 \pm 0,42 \mathrm{Mg} \mathrm{ha}^{-1}$, sendo diferente dos valores de IRR (7,22 $\pm 0,38 \mathrm{Mg}$ $\left.\mathrm{ha}^{-1}\right)$ e CTL $\left(6,95 \pm 0,32 \mathrm{Mg} \mathrm{ha}^{-1}\right)$. No período menos chuvoso, foi encontrado maiores valores no tratamento IRR $\left(6,53 \pm 0,36 \mathrm{Mg} \mathrm{ha}^{-1}\right)$ em comparação a CTL $\left(5,49 \pm 0,22 \mathrm{Mg} \mathrm{ha}^{-1}\right)$, no entanto, o IRR foi similar ao tratamento REM $\left(6,12 \pm 0,31 \mathrm{Mg} \mathrm{ha}^{-1}\right)$ (Figura 5). Em relação a comparação de cada tratamento entre os períodos avaliados, percebe-se que no período chuvoso registrou os maiores valores de liteira estocada para o tratamento CTL e REM, de modo que para o grupo IRR os valores foram similares entre os períodos analisados (Figura 5). 


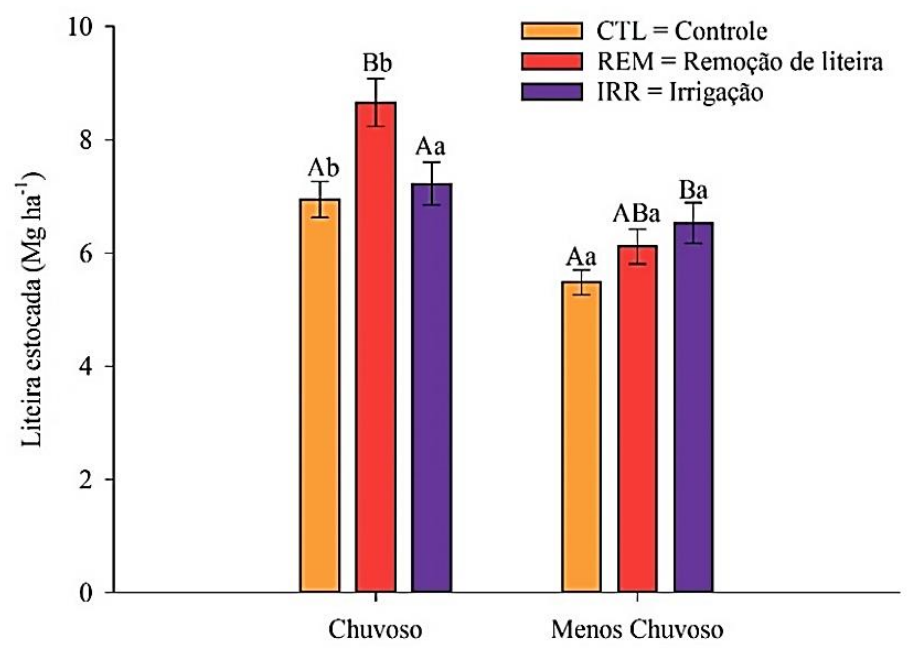

Figura 5: Média \pm EP do estoque de liteira $\left(\mathrm{Mg} \mathrm{ha}^{-1}\right)$ em dois períodos avaliados no ano de 2019, nos tratamentos $C T L=$ controle, $R E M=$ remoção de liteira e IRR= irrigação. Médias seguidas de seus respectivos erros padrões com letras maiúsculas mostram a relação entre os tratamentos no mesmo período; e letras minúsculas mostram a relação de cada tratamento nos períodos avaliados, testado estatisticamente pelo teste de Tukey $(p<0,05)$.

A densidade da liteira entre os tratamentos foi significativamente diferente nos dois períodos avaliados (Figura 6A). O tratamento REM apresentou maior densidade média no período chuvoso $\left(0,011 \pm 0,0005 \mathrm{~g} \mathrm{~cm}^{-3}\right)$, diferindo estatisticamente dos tratamentos IRR $\left(0,009 \pm 0,0005 \mathrm{~g} \mathrm{~cm}^{-3}\right) \mathrm{e}$ CTL $\left(0,009 \pm 0,0004 \mathrm{~g} \mathrm{~cm}^{-3}\right)$ (Figura 6A). Entretanto, no período menos chuvoso, a densidade da liteira foi semelhante entre os tratamentos IRR $\left(0,008 \pm 0,0004 \mathrm{~g} \mathrm{~cm}^{-3}\right)$ e REM $(0,008 \pm 0,0004 \mathrm{~g}$ $\mathrm{cm}^{-3}$ ) (Figura 6A). Quanto a comparação de cada tratamento entre os períodos avaliados, observouse que no período chuvoso ocorreram os maiores valores de densidade da liteira para o tratamento CTL e REM, sendo que para o grupo IRR os valores foram similares entre os períodos analisados (Figura 6A).

A espessura da liteira entre os tratamentos diferiu apenas no período chuvoso com maior valor para o tratamento REM $(1,59 \pm 0,10 \mathrm{~cm})$, comparado a IRR $(1,29 \pm 0,07 \mathrm{~cm})$ e CTL $(1,27 \pm 0,06$ $\mathrm{cm}$ ) (Figura 6B). Entre os períodos, houve diferença apenas para o tratamento IRR com $(1,6 \pm 0,10$ $\mathrm{cm})$ no período menos chuvoso e $(1,29 \pm 0,07 \mathrm{~cm})$ período chuvoso (Figura $6 \mathrm{~B}$ ).

A)

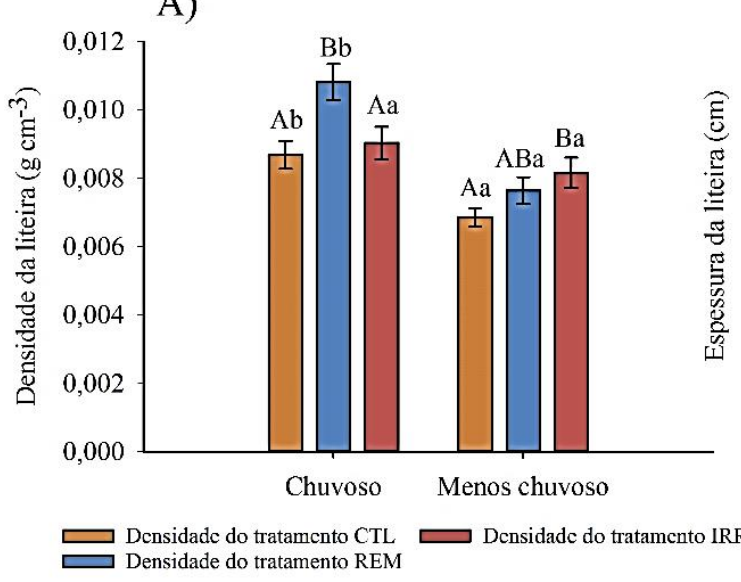

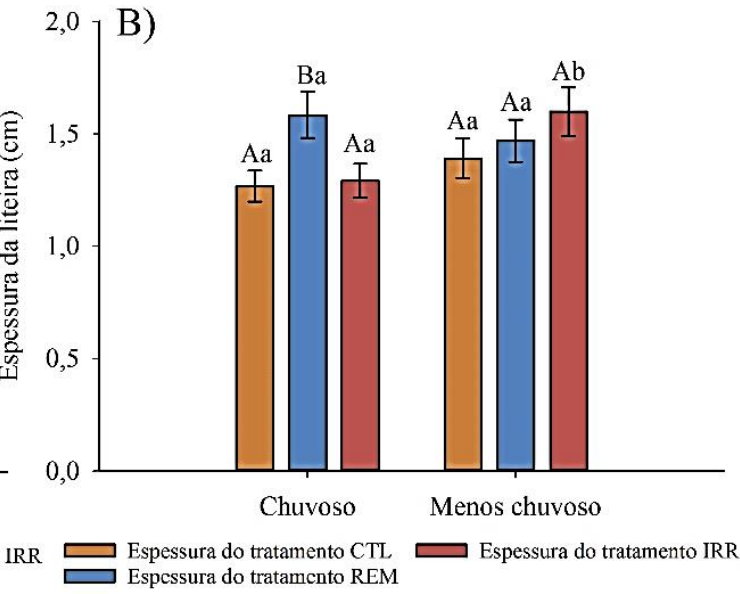

Figura 6: A) Densidade da liteira $\left(\mathrm{g} \mathrm{cm}^{-3}\right)$; B) Espessura (cm) do estoque de liteira, em 2 períodos avaliados no ano de 2019, nos tratamentos $C T L=$ controle, $R E M=$ remoção de liteira e IRR= irrigação. Médias seguidas de seus respectivos erros padrões com letras maiúsculas mostram a relação entre os tratamentos no mesmo período; e letras minúsculas mostram a relação de cada tratamento nos períodos avaliados, testado estatisticamente pelo teste de Tukey $(p<0,05)$. 
A análise da capacidade de retenção hídrica demonstrou que nos dois períodos avaliados houve igualdade entre os tratamentos (Figura 7). Apenas no tratamento IRR foi constatado diferença entre os períodos com $(348,20 \%)$ chuvoso e $(325,44 \%)$ menos chuvoso (Figura 7$)$.

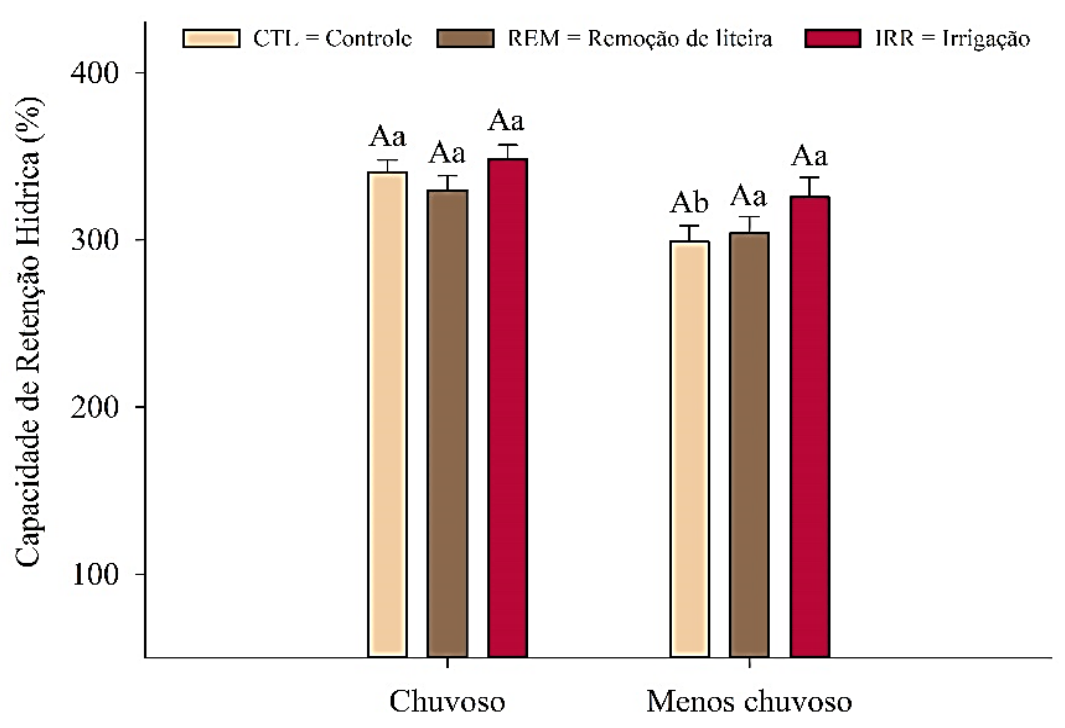

Figura 7: Capacidade de retenção hídrica (\%) em dois períodos avaliados no ano de 2019, nos tratamentos $C T L=$ controle, $R E M=$ remoção de liteira e IRR=irrigação. Médias seguidas de seus respectivos erros padrões com letras maiúsculas mostram a relação entre os tratamentos no mesmo período; e letras minúsculas mostram a relação de cada tratamento nos períodos avaliados, testado estatisticamente pelo teste de Tukey $(p<0,05)$.

\section{DISCUSSÃO}

\subsection{Propriedades físicas da liteira}

Nos tratamentos estudados, a avaliação dos índices de Shannon demonstrou baixa diversidade de espécies em todos os tratamentos, os quais são inferiores aos encontrados para florestas tropicais (que variam entre 3,83 a 5,85) [43], demonstrando um lento processo de recuperação da diversidade. Os valores encontrados para este índice são semelhantes à ecossistemas em restauração em estágio inicial de sucessão localizados na mesma região do presente estudo [44, 45]. A proximidade de centros urbanos e rodovias pode ser uma explicação para o retardamento da restauração ecológica nesta área. Por outro lado, constatamos que a hipótese de que a manipulação de liteira altera o metabolismo das plantas não foi rejeitada (ANOVA, $\mathrm{p}<0,05$ ), tendo em vista a baixa similaridade entre os tratamentos e a maior riqueza de espécies e famílias observada no tratamento IRR, quando comparado ao tratamento REM, demonstra que a manipulação de água, após 12 anos, refletiu efeitos positivos na composição florística. Observamos também que a remoção de liteira pode retardar o desenvolvimento de plantas menos tolerantes às condições edáficas desfavoráveis, pois foi o tratamento que apresentou a menor abundância de indivíduos. Apesar de não termos realizado análise do solo, acreditamos que esses efeitos podem ter ocorrido devido às limitações nutricionais proporcionadas pela remoção de serapilheira, as quais ocorrem a longo prazo [28].

Em contrapartida, estratégias de adaptação morfológicas nas plantas que conseguiram se estabelecer em condições limitantes no tratamento REM, podem tem contribuído para a otimização da utilização dos recursos disponibilizados pelo solo [46]. A rapidez no crescimento de espécies pioneiras, e consequentemente, a mais rápida cobertura do solo, acelera o processo de sucessão ecológica, pois oferece condições de luminosidade ideais para o desenvolvimento de espécies de grupos ecológicos avançados, como secundárias e clímax [47, 48], equilibrando a distribuição dos grupos ecológicos, como aconteceu neste tratamento. 
Nesse cenário, percebemos que a composição florística e a distribuição dos grupos ecológicos podem ter influenciado diretamente nas propriedades físicas da serapilheira. Embora o grupo das pioneiras apresente um rápido crescimento e com isso as árvores liberem grande quantidade de liteira, [49] constataram que em um mesmo intervalo de tempo, os ecossistemas onde predominavam as espécies secundárias ou clímax, apresentando maior quantidade de liteira estocada. Desta forma à medida que o processo de sucessão avança, com a substituição de espécies e predomínio daquelas caracterizadas como secundárias e/ou clímax, haverá possivelmente maior deposição e consequentemente estoque de liteira no solo [50]. Sendo assim, apesar do tratamento REM apresentar menor abundância de indivíduos em relação ao IRR, a igualdade entre eles para o estoque de liteira pode ser evidenciada em razão de três espécies clímax estarem entre as cinco mais importantes no REM, representando 34,06\% de VI (Tabela 1).

Um dos motivos para que isso ocorra é o maior fechamento do dossel, o qual diminui a ação de agentes intempéricos e, por conseguinte, pode diminuir as taxas de decomposição e aumentar o estoque [51]. As espécies clímax representam elevada contribuição para o ciclo biogeoquímico, pois possuem uma extensa área de copa que tendem a predominar no dossel [52], sendo esta variável observada visualmente no tratamento REM. Corroborando com este estudo foi encontrado uma correlação positiva entre a área de copa das espécies e o estoque de liteira, mostrando que quanto mais estruturado e predominante no dossel, maior é sua contribuição no acúmulo de liteira no solo [52].

Quanto ao estoque de liteira nos períodos avaliados, observa-se em outros estudos que os maiores acúmulos acontecem durante o período menos chuvoso [34, 53], principalmente quando o local de estudo apresenta estações climáticas bem definidas. No entanto, esta justificativa não é plausível para a Amazônia, pois o bioma apresenta um clima atípico das outras regiões, com um período de intensa precipitação pluviométrica e outro de menor intensidade (Figura 1). Em ecossistemas com estações climáticas definidas, o aporte de liteira é um mecanismo para a conservação da água, com altos estoques nas estações seca; no entanto, em ecossistemas onde raramente há uma estação seca, como na Amazônia, pode ocorrer uma entrada contínua de liteira ao longo do ano, com picos associados a fatores internos como senescências das espécies; e a fatores ambientais, como tempestades e ventos de chuva [54].

Para este estudo, a relação da liteira estocada de cada tratamento entre os períodos analisados, mostrou que o período chuvoso obteve maior quantidade de massa seca. Isso porque espécies com maior VI nos tratamentos, como T. guianensis, I. alba e $P$. guianensis, tem a floração durante todo o ano, porém com o pico reprodutivo no final do período seco e início do chuvoso, aumentando consideravelmente o estoque de liteira [55]. Somado a isso, este resultado pode ser explicado em decorrência das intensas rajadas de ventos, raios e o próprio peso das gotas da chuva, as quais podem ocasionar ou intensificar o desprendimento dos ramos e das folhas das árvores [6]. Na Amazônia as fortes precipitações pluviométricas afetam a produção e o estoque de liteira de um ecossistema [54]. Outro estudo também na Amazônia, registrou maior acúmulo de liteira no solo no período de maior precipitação pluviométrica, justificado pela maior senescência foliar [17].

Em períodos de maior precipitação pluviométrica é visível constatar menor luminosidade e baixa temperatura nos ecossistemas, ocasionando a redução do processo fotossintético das plantas; gerando assim uma possível senescências das espécies para evitar o alto gasto de energia, sendo isto uma provável explicação fisiológica para este estudo [56]. O acúmulo de material folhoso correlaciona-se positivamente com a precipitação pluviométrica [57]. Entendendo assim, que a senescência das espécies influencia diretamente a quantidade de liteira estocada no solo florestal [50]. Neste contexto, quantificar as frações folhosas e lenhosas pode fornecer informações adicionais para o entendimento do acúmulo de liteira no ecossistema. Como exemplo disso, Londe et al. (2016) [58] mostraram que o estoque da fração lenhosa foi a segunda maior ao longo do ano, justificado pelas ocorrências de ventos fortes que aumentaram a quebra de galhos das árvores. No caso do tratamento REM, o maior estoque de material folhoso e lenhoso é justificado pelo fato de que ecossistemas com menores quantidades de indivíduos, apresentam estrutura simples de vegetação vertical permitindo maior velocidade do vento dentro da floresta, o que resulta na maior queda de galhos e folhas [50].

Costa et al. (2017) [59] registraram 77,1\% de massa folhosa em uma floresta sucessional na Amazônia, o que corrobora com este estudo, afirmando também que a fração foliar é o principal 
componente na manutenção de nutrientes em um ecossistema. Esses valores podem chegar a $80 \%$ em um ecossistema florestal tropical [60]. Quanto aos valores de estoque do fragmento lenhoso, foi observado que a energia mecânica imposta pelo vento durante as chuvas, aliada ao ganho de peso dos galhos pela absorção hídrica foi determinante para a contribuição da massa de liteira estocada no tratamento REM [50].

Este acúmulo do fragmento folhoso e lenhoso gera um valor de densidade e espessura no ecossistema, apresentando uma associação direta com o estoque, pois este apresenta relação com a área, ou seja, com a distribuição da liteira em um hectare. Já a densidade possui relação direta com o volume, sendo a variável altura, descrita neste estudo como espessura da liteira estocada no solo em $\left(\mathrm{g} \mathrm{cm}^{-3}\right)$. Essas variáveis uma vez acumulada contribuem na interceptação de luz, no qual favorece a germinação de sementes, além disso, auxiliam no crescimento e desenvolvimento de microrganismos decompositores e reduzem o processo de erosão e lixiviação do ecossistema [20].

Os altos valores de densidade e espessura são influenciados de maneira mais rápida e efetiva por variáveis climáticas, além das melhores características fitossociológicas das espécies, o que foi constatado no tratamento REM [61]. As alterações quantitativas da densidade e espessura da liteira, junto com a umidade na massa auxiliam na multiplicação de microrganismos decompositores [20]. Vasconcelos et al. (2007) [30], mostraram a importância da umidade na proliferação de macro artrópodes do solo, no qual determinaram a maior perda da massa foliar de liteira. Com o crescimento e desenvolvimento desses decompositores, há uma maior quebra da superfície de adesão da liteira, deixando o material com maior potencial de absorção, obtendo um maior poder de retenção hídrica [49]. Desta forma, em ecossistemas sucessionais alterados, a composição da liteira tem uma grande importância na ciclagem dos nutrientes, pois a liteira estocada e úmida, aliada a fauna decompositora do solo, contribui para a alta disponibilidade de nutrientes solo, sendo essencial para manutenção e conservação do ecossistema [50].

Nos dados sobre a capacidade de retenção hídrica houve igualdade entre os tratamentos avaliados, sendo divergente de outros estudos na Amazônia. Como por exemplo Martins et al. (2018) [8] que encontraram maiores valores no período mais chuvoso, associando a granulometria das frações e ao estágio de decomposição, segundo eles, pequenas partículas de liteira apresentam maior superfície de contato e, portanto, adsorvem mais água; retardando assim, o processo de lixiviação dos nutrientes [62]. A composição das espécies arbóreas pode afetar a capacidade de absorção hídrica da liteira. Martins et al. (2018) [8] analisando a capacidade de retenção hídrica em três ecossistemas diferentes, constataram a evolução da taxa de absorção de acordo com a composição florística de cada ecossistema. Zhou et al. (2018) [63] mostraram que em florestas com maior diversidade de espécies, a absorção hídrica da liteira foi maior [62].

\section{CONCLUSÃo}

De maneira geral, nossos resultados demostraram que o processo de sucessão vem avançando lentamente na floresta. Observamos que as análises das propriedades físicas da liteira aliadas a fitossociologia permitem o entendimento ecológico dos ecossistemas, destacando-se como importantes indicadores de restauração. As propriedades físicas da liteira são semelhantes a ecossistemas mais maduros, porém os parâmetros fitossociológicos ainda não atingiram o padrão de floresta com mais de 30 anos. Após 12 anos do fim dos tratamentos, verificamos que ainda existe diferença entre os tratamentos, proporcionada principalmente pela remoção de liteira. Este tratamento promove efeitos mais significativos na composição florística a longo prazo, e consequentemente, no estoque de liteira do ecossistema, contribuindo para o avanço da sucessão ecológica, devido à possíveis adaptações morfofisiológicas. Destacamos também a necessidade de continuação deste estudo, avaliando outras características ecológicas, como por exemplo produção de liteira, fenologia das espécies e decomposição. 


\section{AGRADECIMENTOS}

A Coordenação de Aperfeiçoamento de Pessoal de Nível Superior - CAPES, Universidade Federal Rural da Amazônia - UFRA, ao Programa de Pós-Graduação em Ciências Florestais PPGCF e o Laboratório de Manejo de Ecossistemas e Bacias Hidrográficas - LABECOS.

\section{REFERÊNCIAS BIBLIOGRÁFICAS}

1. Barlow J, França F, Gardner TA, Hicks CC, Lennox GD, Berenguer E, et al. The future of hyperdiverse tropical ecosystems. Nature. 2018 Jul;559(7715):517-526, doi: 10.1038/s41586-018-0301-1.

2. Oberleitner F, Egger C, Oberdorfer S, Dullinger S, Wanek W, Hietz P. Recovery of aboveground biomass, species richness and composition in tropical secondary forests in SW Costa Rica. For Ecol Manage. 2021 Set;479:118580, doi: 10.1016/j.foreco.2020.118580.

3. Borges SH, Tavares TRS, Crouch NMA, Baccaro F. Sucessional trajetories of bird assemblages in amazonian secondary forests: Perspectives from complementary biodiversity dimensions. For Ecol Manage. 2020;483:118731, doi: 10.1016/j.foreco.2020.118731.

4. Zhang X, Wang B, Liu Z. Impacts of plant secondary metabolites from conifer litter on the decomposition of Populus purdomii litter. J For Res. 2019;30(6):2237-2245, doi: 10.1007/s11676-018-0766-7.

5. Pereira DN, Martins WBR, Andrade VMS, Oliveira FA. Influência da remoção de serapilheira no teor de fósforo e potássio na Amazônia Oriental. Braz J Agric Sci. 2017 Sep;12(3):380-385, doi: 10.5039/agraria.v12i3a5458.

6. Vasconcelos SS, Zarin DJ, Araújo MM, Rangel-Vasconcelos LGT, De Carvalho CJR, Staudhammer CL, et al. Effects of seasonality, litter removal and dry-season irrigation on litterfall quantity and quality in eastern Amazonian forest regrowth, Brazil. J Trop Ecol. 2008 Jan;24(1):27-38, doi: 10.1017/S0266467407004580 .

7. Peng Y., Song S, Li Z, Li S, Chen G, Hu H, et al. Influences of nitrogen addition and aboveground litterinput manipulations on soil respiration and biochemical properties in a subtropical forest. Soil Biol Biochem. 2020 Mar;142:107694, doi: 10.1016/j.soilbio.2019.107694.

8. Martins WBR, Vale RL, Ferreira GC, Andrade VMS, Dionísio LFS, Rodrigues RP, et al. Litterfall, litter stock and water holding capacity in post-mining forest restoration ecosystems, Eastern Amazon. Braz J Agric Sci. 2018 Sep;13(3):1-9, doi: 10.5039/agraria.v13i3a5546.

9. Martins WBR, Ferreira GC, Souza FP, Dionísio LFS, Oliveira FA. Deposição de serapilheira e nutrientes em áreas de mineração submetidas a métodos de restauração florestal em Paragominas, Pará. Floresta. 2018;48(1):37-38, doi: 10.5380/rf.v48i1.49288.

10. Velazco SJE, Galvão F, Keller HA, Bedrij NA. Floristic and phytosociology in a semideciduous seasonal forest - osununú private reserve, Misiones, Argentina. Floresta e Ambient. 2015;22(1):1-12, doi: $10.1590 / 2179-8087.038513$

11. Chaves ADCG, Santos RMS, Santos JO, Fernandes AA, Maracajá PB. A importância dos levantamentos florístico e fitossociológico para a conservação e preservação das florestas. Agropecuária Científica Semiárido. 2013 Jun;9(2):42-48, doi: 10.30969/acsa.v9i2.449.

12. Hillman GR, Golding DL. Inf. rep. NOR-X-234: Forest floor characteristics of marmot and streeter experimental watersheds, Alberta. Edmonton (CA): Canadian Forestry Service; 1981. 21 p.

13. Longhi RV, Longhi SJ, Chami LB, Watzlawick LF, Ebling AA. Produção de serapilheira e retorno de macronutrientes em três grupos florísticos de uma Floresta Ombrófila Mista, RS. Ciência Florest. 2011 Out;21(4):699-710, doi: 10.5902/198050984514.

14. Kimmins JP. Forest ecology. A foundation for sustainable management. 2nd ed. Minnesota (US): Prentice Hall, Biogeochemistry; 1987. Chapter 5, Cycling os Nutrients in Ecosystems; p. 68-129.

15. Rodrigues BD, Martins SV, Leite HG. Avaliação do potencial da transposição da serapilheira e do banco de sementes do solo para restauração florestal em áreas degradadas. Rev Árvore. 2010 Feb;34(1):65-73, doi:10.1590/S0100-67622010000100008.

16. Vendrami JL, Castanho CT, Lorenzo L, Oliveira AA, Jurinitz CF. Litterfall and leaf decomposition in forest fragments under different successional phases on the Atlantic Plateau of the state of Sao Paulo, Brazil. Biota Neotrop. 2012;12(3):136-143, doi: 10.1590/S1676-06032012000300016.

17. Tonin AM, Gonçalves JF, Bambi P, Couceiro SEM, Feitoza LAM, Fontana LE, et al. Plant litter dynamics in the forest-stream interface: Precipitation is a major control across tropical biomes. Sci Rep. 2017 Dec;7(1):1-14, doi: 10.1038/s41598-017-10576-8.

18. Mendoza Z, Borges P, Oliveira J, Siqueira T, Morais P. Propriedades físicas da serapilheira de teca. Enciclopédia Biosf. 2018 Jun;15(27):1411-1423, doi: 10.18677/EnciBio_2018A121. 
19. Facelli JM, Pickett STA. Plant litter: Its dynamics and effects on plant community structure. Bot Rev. 1991 Jan;57(1):1-32, doi: 10.1007/BF02858763.

20. Lima RP, Fernandes MM, Fernandes MRM, Matricardi EAT. Aporte e decomposição da serapilheira na Caatinga no Sul do Piauí. Floresta e Ambient. 2015;22(1):42-49, doi: 10.1590/2179-8087.062013.

21. Zhang H, Yuan W, Dong W, Liu S. Seasonal patterns of litterfall in forest ecosystem worldwide. Ecol Complex. 2014 Dec;20(8):240-247, doi: 10.1016/j.ecocom.2014.01.003.

22. Parton WJ, Stewart JWB, Cole CV. Dynamics of C, N, P and S in grassland soils: a model. Biogeochem. 1988 Feb;5(1):109-131, doi: 10.1007/BF02180320.

23. Fernandes MM, Pereira MG, Magalhães LMS, Cruz AR, Giácomo RG. Aporte e decomposição de serapilheira em áreas de floresta secundária, plantio de sabiá (Mimosa caesalpiniaefolia Benth.) e andiroba (Carapa guianensis Aubl.) na Flona Mário Xavier, RJ. Ciência Florest. 2006 Jun;16(2):163175, doi: 10.5902/198050981897.

24. Sayer EJ. Using experimental manipulation to asses the roles of leaf litter in the functionong of forest ecosystems. Biol Rev Camb Philos Soc. 2006;81(1):1-31, doi: 10.1017/S1464793105006846.

25. Sayer EJ, Tanner EVJ. Experimental investigation of the importance of litterfall in lowland semievergreen tropical forest nutrient cycling. J Ecol. 2010;98(5):1052-1062, doi: 10.1111/j.13652745.2010.01680.x.

26. Liu R, Zhang Y, Hu XF, Wan S, Wang H, Liang C, et al. Litter manipulation effects on microbial communities and enzymatic activities vary with soil depth in a subtropical Chinese fir plantation. For Ecol Manage. 2021;480:118641, doi: 10.1016/j.foreco.2020.118641.

27. Vasconcelos SS, Zarin DJ, Capanu M, Littell R, Davidson EA, Ishida FY, et al. Moisture and substrate availability constrain soil trace gas fluxes in an eastern Amazonian regrowth forest. Global Biogeochem Cycles. 2004;18(2):1-10, doi: 10.1029/2003GB002210.

28. Araújo MM, Tucker JM, Vasconcelos SS, Zarin DJ, Oliveira W, Sampaio PD, et al. Padrão e processo sucessionais em florestas secundárias de diferentes idades na Amazônia Oriental. Ciência Florest. 2005 Dec;15(4):343-357, doi: 10.5902/198050981872.

29. Rangel-Vasconcelos LGT, Zarin DJ, Carvalho CJR, Santos MMLS, Vasconcelos SS, Oliveira FA. Carbono, nitrogênio e atividade da biomassa microbiana de um solo sob vegetação secundária de diferentes idades na Amazônia oriental. Rev Ciências Agrárias. 2005 Jul;(44):49-63.

30. Vasconcelos SS, Zarin DJ, Rosa MBS, Oliveira FA, Carvalho CJR. Leaf Decomposition in a dry season irrigation experiment in eastern Amazonian Forest regrowth. Biotropica. 2007 Dec;35(5):593-600, doi: 10.1111/j.1744-7429.2007.00313.x.

31. Fortini LB, Bruna EM, Zarin DJ, Vasconcelos SS, Miranda IS. Altered resource availability and the population dynamics of tree species in Amazonian secondary forests. Oecologia. 2010 Apr;162(4):923934, doi: 10.1007/s00442-009-1524-5.

32. Lima TTS, Miranda IS, Vasconcelos SS. Effects of water and nutrient availability on fine root growth in eastern Amazonian forest regrowth, Brazil. New Phytol. 2010 Apr;187(3):622-630, doi: 10.1111/j.14698137.2010.03299.x.

33. Lima TTS, Miranda IS, Vasconcelos SS. Fine-root production in two secondary forest sites with distinct ages in Eastern Amazon. Acta Amaz. 2012;42(1):95-104, doi: 10.1590/S0044-59672012000100012.

34. Vasconcelos SS, Zarin DJ, Araújo MM, Miranda IS. Aboveground net primary productivity in tropical forest regrowth increases following wetter dry-seasons. For Ecol Manage. 2012 Mar;276:82-87, doi: 10.1016/j.foreco.2012.03.034.

35. Tenório ARM, Graça JJC, Góes JEM, Mendez JGR, Gama JRMF, Silva PRO, et al. Mapeamento dos solos da estação de piscicultura de Castanhal, PA. Belém (PA): UFRA; 1999. (FCAP: Inf. Técnico, 25).

36. Coelho RFR, Zarin DJ, Miranda IS, Tucker JM. Análise florística e estrutural de uma floresta em diferentes estágios sucessionais no município de Castanhal, Pará. Acta Amaz. 2003 Dec;33(4):563-582, doi: 10.1590/S0044-59672003000400004.

37. Martorano LG, Pereira LC, Nechet D. Tipologia climática do Estado do Pará: adaptação do método de Köppen. Bol Geogr Teorética. 1993;23:45-46.

38. INMET. Instituto Nacional de Meteorologia Banco de dados meteorológicos [Internet]. Ministerio da agricultura, pecuária e abastecimento. 2019 [citado em 12 fev 2021]. Disponível em: https://bdmep.inmet.gov.br/

39. Kuchler AW, Mueller-Dombois D, Ellenberg H. Aims and methods of vegetation ecology. Geogr Rev. 1976 Jan;66(1):45-66.

40. Souza AL, Soares CPB. Florestas nativas: estrutura, dinâmica e manejo. Viçosa (MG): UFV; 2013. 322 p.

41. Budowski G. Distribution of tropical American rain forest species in the light of successional processes. Turrialba. 1965;15(1):40-42. 
42. Blow FE. Quantity and hydrologic characteristics of litter upland oak forest in Eastern Tennessee. J For. 1955;53(3):190-195, doi: 10.1093/jof/53.3.190.

43. Knight DH. A Phytosociological analysis of species-rich tropical forest on Barro Colorado Island, Panama. Ecol Monogr. 1975;45(3):259-284, doi: 10.2307/1942424.

44. Rodrigues MACM, Miranda IS, Kato MAS. Estrutura de florestas secundárias após dois diferentes sistemas agrícolas no nordeste do estado do Pará, Amazônia Oriental. Acta Amaz. 2007;37(4):4:591-598, doi: 10.1590/S0044-59672007000400014.

45. Coutinho FS, Pereira MG, Menezes CEG, Guareschi RF, Assunção SA. Atributos edáficos em áreas de agricultura, pastagem e três estágios sucessionais de floresta. Floresta e Ambiente. 2017;24:e00091914, doi: 10.1590/2179-8087.091914.

46. Liu K, Liang T, Qiang W, Du G, Baskin JM, Baskin CC, et al. Changes in seed germination strategy along the successional gradient from abandoned cropland to climax grassland in a subalpine meadow and some implications for rangeland restoration. Agric Ecosyst Environ. 2020 Nov;289:106746, doi: 10.1016/j.agee.2019.106746.

47. Foronda A, Pueyo Y, Castillejo JM, Giner ML, Alados CL. Substrate-specialist plants for restoring vegetation in post-mining gypsum substrates. Catena. 2020;186:104308, doi: 10.1016/j.catena.2019.104308.

48. Pietrzykowski M. Tree species selection and reaction to mine soil reconstructed at reforested post-mine sites: Central and eastern European experiences. Ecol Eng X. 2019;3:100012, doi: 10.1016/j.ecoena.2019.100012.

49. Mateus FA, Miranda CC, Valcarcel R, Figueiredo PHA. Estoque e capacidade de retenção hídrica da serrapilheira acumulada na restauração florestal de áreas perturbadas na Mata Atlântica. Floresta e Ambient. 2013;20(3):336-343, doi: 10.4322/floram.2013.024.

50. Silva WB, Périco E, Dalzochio MS, Santos M, Cajaiba RL. Are litterfall and litter decomposition processes indicators of forest regeneration in the neotropics? Insights from a case study in the Brazilian Amazon. For Ecol Manage. 2018 Jul,429:189-197, doi: 10.1016/j.foreco.2018.07.020.

51. Lebrija-Trejos E, Perez-Garcia EA, Meave JA, Poorter L, Bongers F. Environmental changes during secondary succession in a tropical dry forest in Mexico. J Trop Ecol. 2011;27(5):477-489, doi: 10.1017/S0266467411000253.

52. Lorenzo L, Campagnaro VH. Litterfall production as a function of planting seedlings system in a two years forest restoration area in the coastal-plain of Caraguatatuba, São Paulo, Brazil. Rev Árvore. 2017 Jun;41(2):1-8, doi: 10.1590/1806-90882017000300019.

53. Souza MA, Souto JS, Andrade AP, Araujo KD, Gomes DL. Contribution of litter and leaf decomposition of Byrsonima gardneriana. Floresta e Ambient. 2018 Dec;26(1):1-10, doi: 10.1590/2179-8087.037616.

54. Lemes da Silva AL, Lisboa LK, Siegloch AE, Petrucio MM, Gonçalves-Júnior JF. Connecting the litterfall temporal dynamics and processing of coarse particulate organic matter in a tropical stream. Mar Freshw Res. 2017 Oct;68(7):1260, doi: 10.1071/MF16032.

55. Dray WT, Leal Filho N. Fenologia de espéicies pioneiras arbóreas amazônicas. In: Anais da XX Jornada Iniciação Científica PIBIC INPA - CNPq/FAPEAM; 2011; Manaus.

56. Pes LZ, Arenhardt MH. Fisiologia vegetal. Santa Maria (RS): Universidade Federal de Santa Maria, Colégio Politécnico, Rede e-Tec Brasil; 2015. 81 p.

57. Santos RS, Barreto-Garcia PAB, Scoriza RN. Fungos micorrízicos arbusculares e serapilheira como indicadores do efeito de borda em fragmento de floresta estacional. Ciência Florest. 2018 Apr;28(1):324335, doi: 10.5902/1980509831603.

58. Londe V, De Sousa HC, Kozovits AR. Litterfall as an indicator of productivity and recovery of ecological functions in a rehabilitated riparian forest at das velhas river, southeast Brazil. Trop Ecol. 2016;57(2):355360.

59. Costa BC, Suzuki PM, Martins WBR, Andrade VMS, Oliveira FA. Dinâmica da massa seca e propriedades químicas da liteira em Virola surinamensis e floresta sucessional na Amazônia oriental. Rev Verde Agroecol Desenvolv Sustentável. 2017 May;12(1):1-23, doi: 10.18378/rvads.v12i1.4407.

60. Terror VL, Sousa HC, Kozovits AR. Produção, decomposição e qualidade nutricional da serapilheira foliar em uma floresta paludosa de altitude. Acta Bot Brasilica. 2011 Mar;25(1):113-121, doi: 10.1590/S0102-33062011000100014.

61. Barbosa V, Barreto-Garcia P, Gama-Rodrigues E, De Paula A. Biomassa, carbono e nitrogênio na serapilheira acumulada de florestas plantadas e nativa. Floresta e Ambient. 2017;24(1):1-9, doi: 10.1590/2179-8087.024315.

62. Xia L, Song X, Fu N, Cui S, Li L, Li H, et al. Effects of forest litter cover on hydrological response of hillslopes in the Loess Plateau of China. Catena. 2019 Oct;181:1-11, doi: 10.1016/j.catena.2019.104076.

63. Zhou Q, Keith DM, Zhou X, Cai M, Cui X, Wei X, et al. Comparing the water-holding characteristics of broadleaved, coniferous, and mixed forest litter layers in a Karst Region. Mt Res Dev. 2018 Aug;38(3):220-229, doi: 10.1659/mrd-journal-d-17-00002.1. 